\title{
Viewpoint
}

\section{Missing link in the audit cycle}

\author{
Iain K Crombie, Huw T O Davies
}

Effecting change in the delivery of health care is recognised as the major challenge facing audit. ${ }^{12}$ Reviews of audit have found that many studies have led to the feedback of information describing defects in medical practice, but in only a few is it clear that the shortcomings have been overcome. ${ }^{2-4}$ We argue that part of the explanation for the lack of success in improving the quality of care is that a step essential to audit has been omitted from the conventional presentation of the audit cycle.

\section{Missing link}

The conventional audit cycle ${ }^{5}$ compares current practice against a standard; if care is less than satisfactory attempts are made to effect change in order to improve the quality of care. The difficulty is that simply recognising a deficiency does not necessarily identify what has to be changed or how. The missing link is the step which identifies why current practice fails to meet the standard (figure).

It is not sufficient to establish that a problem exists, or even to describe it in detail. Once a problem has been identified the underlying causes need to be sought and understood. Solving the problem should then be possible. This process may seem self evident, but its consequences have been curiously absent from many audit studies. The significance of missing this essential step can be seen by contrasting two recent audit studies of the management of trauma.

Sharples et al were concerned about head injuries in children because these were a major cause of death and because previous studies had shown that "up to $30 \%$ of those who died

Department of Epidemiology and Public Health, Ninewells Hospital and Medical School

Dundee DD1 9SY

Iain K Crombie, senior

lecturer

Huw T O Davies,

research fellow

Correspondence to: Dr Crombie

Accepted for publication

14 December 1992

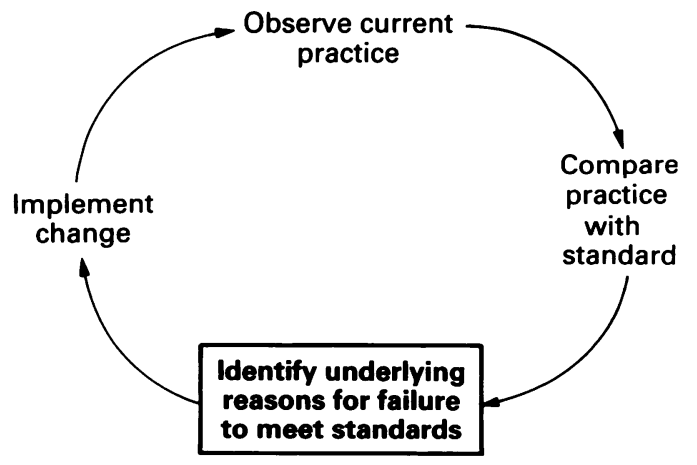

Missing link in audit cycle had potentially avoidable secondary complications that probably contributed to death." 6 The audit study which they had conducted showed that in $32 \%$ of children who died of head injury in the Northern region during 1979-86 there were potentially avoidable factors. The study went a step further and also described the aspects of management in which the problems lay. These included "failure of diagnosis or delayed recognition of intracranial haemorrhage or associated injury, inadequate management of the airways, and poor management of the transfer between hospitals." But the fundamental reasons for these management deficiencies were not identified. The authors concluded that regional guidelines for neurosurgical referral should include the assessment of children with severe head injuries. They also suggested that regions should audit their management of all patients with head injuries.

A separate study assessed the quality of medical care of severely injured patients seen at an accident and emergency department. ${ }^{7}$ As in the previous example management errors were common, occurring in 21 of the 36 patients seen. The area of care in which errors were most common was also noted, in this case management of blunt trauma as opposed to penetrating trauma. But the authors took the investigation one stage further and identified the underlying causes of the management errors. They found that errors were most common "outside normal office hours when only inexperienced junior doctors staffed the department." Then instead of simply recommending that guidelines should be revised, they specified the precise alterations to practice that were required: "that staffing arrangements be changed so that newly qualified doctors are not left alone to deal with this type of patient." A scoring system was developed so that serious cases could be recognised quickly and junior doctors were advised to contact senior colleagues about their management. A second audit disclosed that these changes led to a $50 \%$ reduction in management errors. ${ }^{8}$

The key to effecting change in health care lies in establishing the causes of deficiencies. These causes point directly to possible solutions which can be tailored exactly to the problem. Many audits adopt customary approaches to effecting change, such as feedback of information on current practice or issuing general management guidelines to all 
staff. Yet if the underlying causes have been identified detailed guidance on specific topics can be given to those staff who need it most. A precise specification of the underlying causes also provides stimulus to implementing a solution. It is difficult not take action when you know exactly what is needed to improve the delivery of health care.

The relevance of the missing link is not limited to the two examples given but is evident in other recently published audit studies. For example, Lewis et al found that some patients with myocardial infarction did not receive thrombolytic therapy within 24 hours. ${ }^{9}$ In these patients a definite diagnosis was not made in time because important information about the activities of serum creatinine kinase was being delayed. Establishing an emergency service for obtaining these results resolved this difficulty, and the care for these patients improved. In another study $45 \%$ of central venous catheters had to be removed because of sepsis. ${ }^{10}$ The authors then searched for "possible causes of this alarmingly high rate" and discovered that " $40 \%$ of medical and nursing staff were observed to follow an incomplete hand washing technique." Correct technique was taught as part of an intensive educational programme, with the result that the incidence of sepsis fell to $8 \%$.

The final example is of a study which did not succeed in effecting change. Because of concerns that some caesarean sections might be unwarranted, consensus guidelines recommending decreases in the use of caesarean section were distributed to obstetricians. Although almost all obstetricians were aware of the guidelines and agreed with them there was "only a slight change from the previous upward change". "The authors concluded that guidelines by themselves are unlikely to effect change and that other incentives or disincentives were needed. Perhaps if the true reasons for the high rate of caesarean section had been identified and interventions directed accordingly, the study might have had more success.

\section{Conclusions}

The process of effecting change in the delivery of health care may be viewed as occurring in three stages: confirming the existence of a problem; identifying the reasons for its occurrence; and developing and implementing the strategy for change. We have argued that although many audit studies describe deficiencies in health care, few identify the underlying causes. In consequence, the strategies for change which are developed may not address the fundamental problems. An important link in the audit cycle is missing, and failure to include this step is hampering the success of audit.

This step in the audit cycle is clearly not the only difficulty in effecting change in clinical practice. There are many barriers to implementing a strategy for change successfully, and techniques for overcoming them have been reviewed. ${ }^{12-15} \mathrm{~A}$ recent series of seven papers explored in detail how change can be implemented in general practice. ${ }^{15-21}$ However, attention to the principles of implentation will not guarantee success; even if all the barriers to change are overcome, a strategy will be unsuccessful unless it is targeted at the underlying causes of the health care problem. There may be more than one reason for substandard care, and for each reason there may be a different solution.

The importance of seeking and understanding the underlying causes of poor quality care has not been emphasised. Many authors fail to report these details even when it is a (possibly unplanned) feature of their study. Thus the real test of the value of our thesis will be whether it is used in practice in the future. The test can be phrased as a question: will audits which seek out underlying causes of healthcare problems be more successful than audits which do not? We are confident that this will prove to be the case.

IKC and HTOD are supported by the Scottish Home and Health Department; HTOD was also supported by the Ian Mactaggart Trust and the North British Pain Association.

1 Smith T. Medical audit. BMF 1990;300:65

Mitchell MW, Fowkes FGR. Audit reviewed: does feedback on performance change clinical behaviour? $\mathcal{F} R \mathrm{Coll}$ Phys Lond 1985;19:65.

3 Mugford M, Banfield P, O'Hanlon M. Effects of feedback of information on clinical practice: a review. BMF 1991; of information

4 Yudkin PL, Redman CWG. Obstetric audit using routinely collected computerised data. $B M F$ 1990;301:1371-3

Fowkes FGR. Medical audit cycle. Med Educ 1982;16: 228-38

6 Sharples PM, Storey A, Aynsley-Green A, Eyre JA. Avoidable factors contributing to death of children with head injury. $B M \mathcal{F}$ 1990;300:87-91.

7 Dearden $\mathrm{CH}$, Rutherford WH. The resuscitation of the severely injured in the accident and emergency department - a medical audit. Injury 1985;16:249-52.

8 Fisher RB, Dearden CH. Improving the care of patients with major trauma in the accident and emergency with major trauma in the accident

9 Lewis F, Jishi F, Sissons CE, Baker JT, Child DF. Value of emergency cardiac enzymes: audit in a coronary care unit. FR Soc Med 1991;84:398-9.

10 Puntis JWL, Holden CE, Smallman S, Finkel Y, George RH, Booth IW. Staff training: a key factor in reducing intravascular catheter sepsis. Arch Dis Child 1990;65: 335-7.

11 Lomas J, Anderson GM, Domnick-Pierre K, Vayda E, Enkin MW, Hannah WJ. Do practice guidelines guide practice? The effect of a consensus statement on practice? The the of physicians. $N$ Engl f Med 1989;304: the practice

12 Spiegal N, Murphy E, Kinmouth A-L, Ross F, Bain J, Coates R. Managing change in general practice: a step by step guide. $B M \mathcal{F} 1992 ; 304: 231-4$

13 Berwick DM, Enthoven A, Bunker JP. Quality management in the NHS: the doctor's role. I. BMF 1992;304: 235-9.

14 Berwick DM, Enthoven A, Bunker JP. Quality management in the NHS: the doctor's role. II. BMF 1992;304: 304-8.

15 Atkinson C, Hayden J. Strategies for success. BMF 1992; 304:1488-90.

16 Pringle $M$. Managing change in general practice: introduction. $B M F$ 1992:304:1357-8.

17 Allen J, Wilson A. Learning from the past. BMF 1992;304:

18 Scott MGB, Marinker $M$. Imposed change in general practice. $B M \mathcal{1}$ 1992;304:1548-50.

practice. $B M \mathcal{F} 1992 ; 304: 1548-50$.
19 Hobbs FDR, Drury M. Meetings and chairmanship. $B M F$ 1992;304:1616-8.

20 Macmillan L, Pringle $M$. Practice managers and practice management. BMF 1992;304:1672-4.

21 Metcalfe $D$. The chains of education, experience, and culture. $B M \mathcal{F}$ 1992;305:33-4. 